\title{
Simulation of Rocket Exhaust Clouds at the Centro de Lançamento de Alcântara Using the WRF-CMAQ Modeling System
}

\author{
Erick Giovani Sperandio Nascimento", Davidson Martins Moreira2,3, Gilberto Fisch², \\ Taciana Toledo de Almeida Albuquerque ${ }^{1}$
}

\begin{abstract}
In this work we report numerical simulations of the contaminant dispersion and photochemical reactions of rocket exhaust clouds at the Centro de Lançamento de Alcântara (CLA) using the CMAQ modeling system. The simulations of carbon monoxide (CO), hydrogen chloride $\left(\mathrm{HCl}\right.$ ) and alumina (solid $\mathrm{Al}_{2} \mathrm{O}_{3}$ ) pollutants emission represent an effort in the construction of a computational tool in order to simulate normal and/or accidental events during rocket launches, making possible to predict the contaminant concentrations in accordance with emergency plans and pre and post-launchings for environmental management. The carbon monoxide and the alumina concentrations showed the formation of the ground and contrail cloud. The results also showed that hydrogen chloride concentrations would be harmful to human health, demonstrating the importance of assessing the impact of rocket launches in the environment and human health.
\end{abstract}

KEYWORDS: Centro de Lançamento de Alcântara, Rocket launch, $C M A Q$, Dispersion modeling.

\section{INTRODUCTION}

An important and singular air pollution problem is related to rocket launches. The burning of rocket engines during the first few seconds prior to and immediately after vehicle launchings results in the formation of a large cloud of hot, buoyant exhaust products near ground level, which subsequently rises and entrains ambient air until the temperature and density of the cloud reach an approximate equilibrium with ambient conditions. The United States' space activities are conducted by military personel (Air Force) and civilians (NASA). The US Air Force has 2 rocket launching centers, being one at the east coast at Cape Canaveral Air Force Base (AFB), in Florida, and another one at the west part, at Vandenberg AFB, California. These launching centers are close to big and populated region/cities which may be affected by the gases released during the launchings. In order to estimate the risks and environmental impacts associated to the launchings (either normal or failed ones), a special model named Rocket Exhaust Effluent Diffusion Model (REEDM) was developed by Bjorklund et al. (1982). This model assumes a constant wind profile and Gaussian plume turbulence to access the movement of the clouds derived from the exhausted gases. According to Nappo and Essa (2001), despite the fact that the REEDM model was operationally used for a long time (since the 1980s), it may not be fully checked using field data collected over the US launching centers. During the period from 1995 up to 1997, a Model Validation Program (MVP) was established to address these concerns and several field experiments with special tracers made at Cape Canaveral AFB and Vandenberg AFB. Furthermore, regarding the numerical simulations for the prediction of rocket exhaust flow fields, we can cite the works of Reis et al. (1970) and Rao et al. (2001).

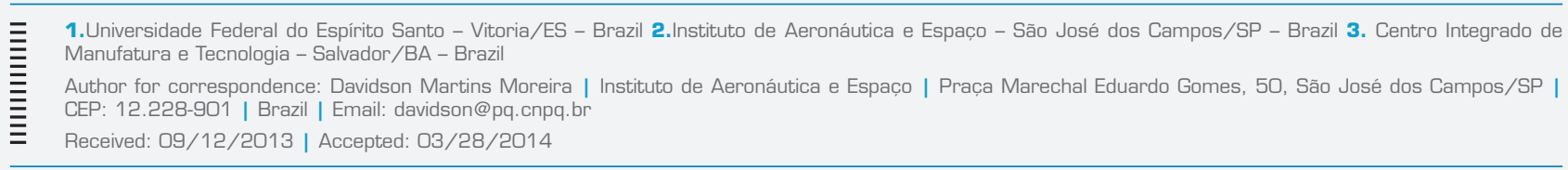


Unfortunately, there is no model fully ready to meet these demands in Brazil, or some experimental data dispersion of contaminants related to the Centro de Lançamento de Alcântara (CLA). Therefore, researches are very important as well as the developing of a modeling system designed to calculate peak concentrations, dosage and deposition (resulting from both gravitational settling and precipitation scavenging), downwind from normal and aborted launchings, to be used in mission planning activities and environmental assessments, pre-launch forecasts of the environmental effects of launch operations and post-launch environmental analysis in the Brazilian site. To this end, this paper aims at providing a framework which will allow the development of a model that considers the Brazilian site's characteristics. Therefore, the main purpose of this study is to report a numerical study (numerical experiment) of the contaminant dispersion and photochemical reactions for the pollutants $\mathrm{HCl}, \mathrm{Al}_{2} \mathrm{SO}_{3}$ and $\mathrm{CO}$ in CLA using the Community Multi-scale Air Quality (CMAQ) modeling system. The paper describes the main CMAQ changes needed to incorporate rocket launches in this modeling system. In fact, CMAQ is a multipollutant, multiscale air quality model that contains state-of-science techniques for simulating all atmospheric and land processes which affect the transport, transformation, and deposition of atmospheric pollutants and/or their precursors on both regional and urban scales (Byun e Ching, 1999). These simulations represent an effort in the construction of a computational tool for normal and/or accidental events during rocket launches, making it possible to both predict and simulate the concentration needed, in accordance to emergency plans and pre and post-launchings for environmental management.

\section{THE MODELING SYSTEM}

The CMAQ model is a fully 3-dimensional modeling system consisting of three main components (meteorology, emissions and a chemical model) and various interfaces. Therefore, with this modular structure, the CMAQ has enough flexibility to change other meteorological models and emissions modeling systems (Byun and Ching, 1999). It is important to mention that the CMAQ model is a state-of-the-art modeling tool in air quality problems.

\section{SITE DESCRIPTION}

The CLA is the space gate of Brazil and it is located at the North part of Brazil (2 degrees south), close to Equator (Fig. 1).
More information about the CLA, its topography and climate can be found at Pires et al. (2009).

Climatologically, there is a very distinctive rainfall characteristic: a wet season from January up to June, with highest rainfall in March and April (monthly rainfall about $300 \mathrm{~mm} / \mathrm{mo}$ ) and a dry season from July up to December (rainfall almost null or very low - less than $30 \mathrm{~mm} / \mathrm{mo}$ ). The winds follow this climatic behavior presenting high wind speed during the dry season (winds around 7-8 m/s at $70 \mathrm{~m}$ height) and a moderate winds (winds around 5-6 m/s) during the wet season. To represent this behavior, it was released a radiosonde in the CLA on April $2^{\text {nd }}, 2010$. The radiosonde uses a Vaisala Oy system (sonde RSV92G), which is the state-of-art in terms of upper air measurements. The winds (wind speed and direction up to 5,000 m) are presented at Fig. 2 and they are quite characteristic for the wet season: there is a linear increase of the wind speed from the surface up to a maximum value of approximately $16 \mathrm{~m} / \mathrm{s}$ at 3,000 m. Between 2,000 and 4,000 m, the winds are very persistent, ranging from $14-16 \mathrm{~m} / \mathrm{s}$. The direction of the wind is NE/E (around $60^{\circ}$ at $500 \mathrm{~m}$ ) and then rotating southward (around $100-110^{\circ}$ ). The synoptic pattern is typical from the wet season, with the intertropical convergence zone (ITCZ) reaching the north part of Brazil, with a large cloud cluster over the ocean and inland at the CLA (Fig. 3).

Figure 4 presents the modeling domains. These domains were modeled using the Weather Research and Forecasting (WRF) Model (version 3.3) (Skamarock and Klemp, 2008) to generate meteorological fields in a one-day simulation. The horizontal

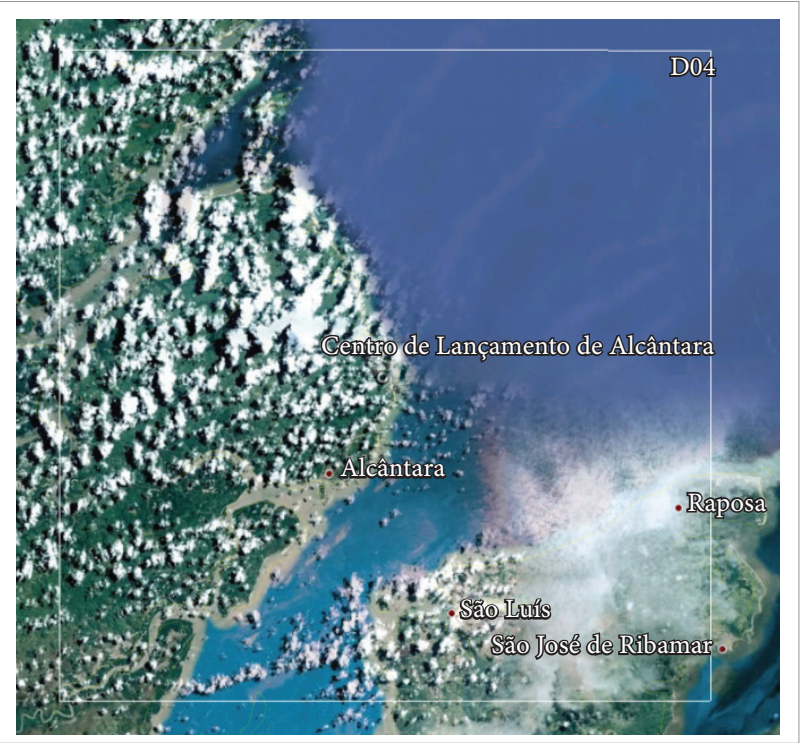

Figure 1. The location of the domain used in CMAQ to model the rocket launch case. 
resolutions of the nested grid were $27 \mathrm{~km}, 9 \mathrm{~km}, 3 \mathrm{~km}$ and $1 \mathrm{~km}$, and the horizontal dimensions, in grid cells, were $36 \times 36,54 \times 54$, $84 \times 84$ and 66 x 66, for domain 1 to 4, respectively. Recently, Silva and Fisch (2014) did a detailed analysis about the use of WRF for the CLA using radiosonde data collected during dry (2008) and wet season (2010) as a comparison. They found that the WRF, using the default parameterizations, can represent the wind speed at the site reasonably well (difference between the model and the observed is less than $2.0 \mathrm{~m} / \mathrm{s}$ ). The innermost domain, highlighted in Fig. 1, was used in order to model a hypothetical average rocket launch event in CLA using the CMAQ model, version 5.0.1 (Byun and Schere, 2006).

In order to run the WRF model to properly generate the meteorological fields, we used final analysis data from the Global Forecast System (GFS) with a resolution of 1 arc degree. Figure 5 presents the surface wind field simulated by the WRF model at the time of the launch (April $2^{\text {nd }}, 2010-2-5 \mathrm{PM}$ ). It is possible to note that the wind is predominantly blowing in the opposite direction of the large city of São Luís and in the direction of an inhabited area, and it keeps on until later in the same day, at 9PM local time,

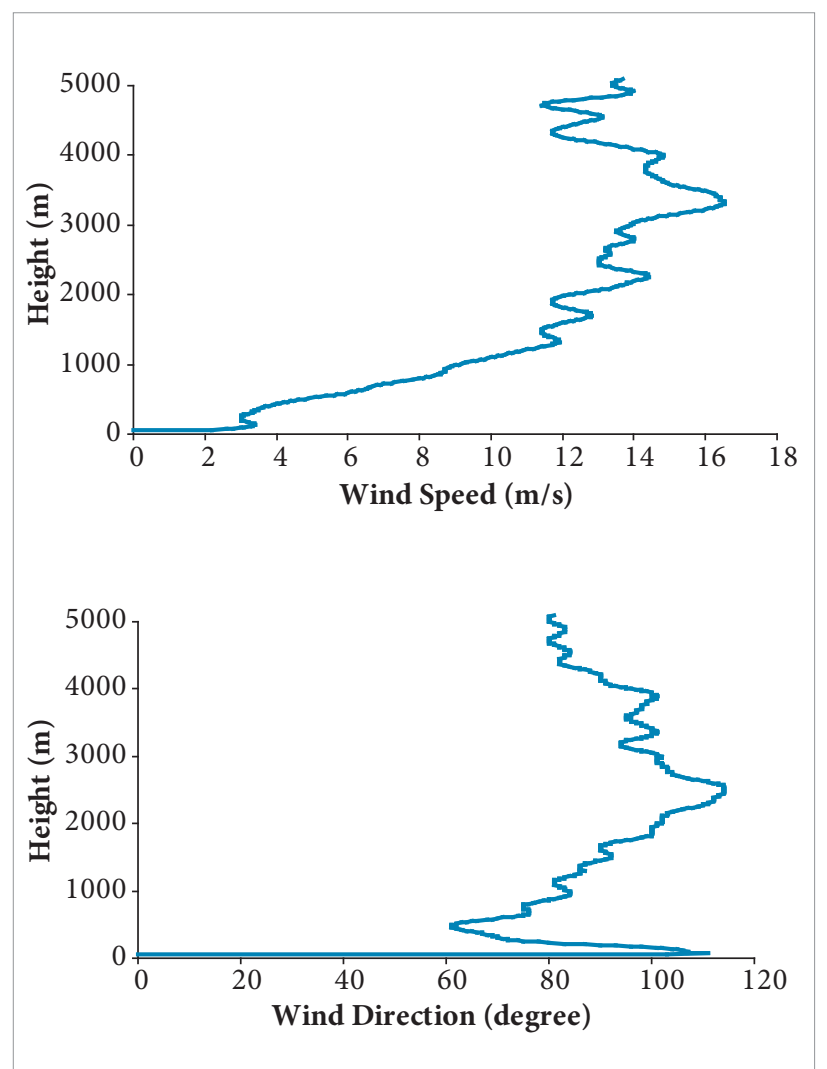

Figure 2. The wind profile at CLA for April $2^{\text {nd }}$, 2010. when the wind field entirely changes and it starts blowing in the direction of the city of São Luís. This situation, which is presented in Fig. 6, shows that a major concern is to determine when launching operations should be released, in order to prevent the environmental impact and air contamination of a metropolitan area, due to the large cloud of hazardous pollutants generated by the launch. In this simulation, the pollutants were already been dispersed to out of the domain at the time when the wind field changed, meaning that there were no more environmental risk of the cloud reaching the city of São Luís, as observed in the "Results and Discussion" section.

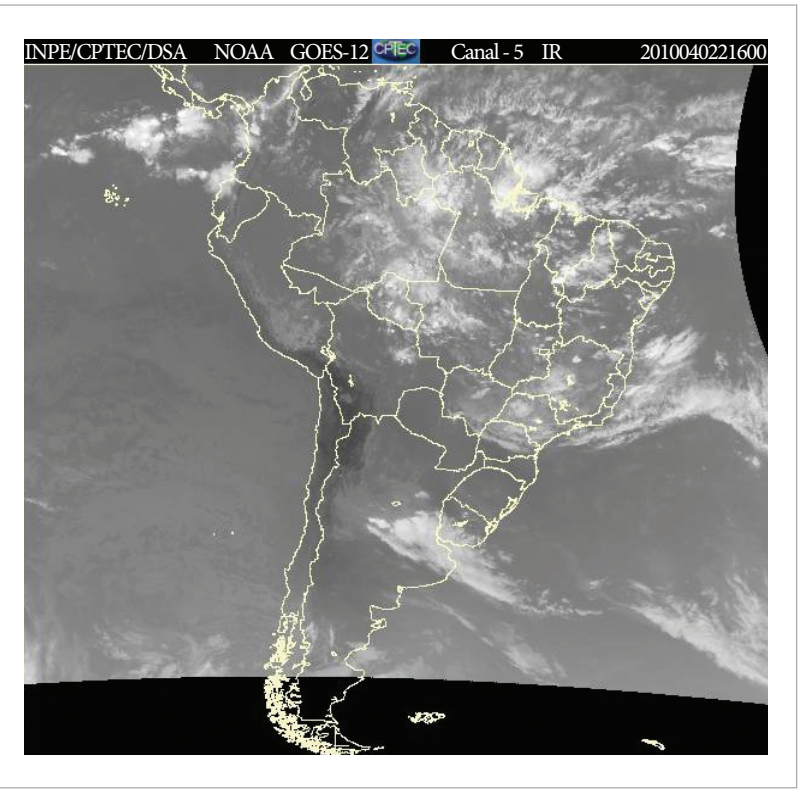

Figure 3. The synoptic pattern for April 2nd, 2010.

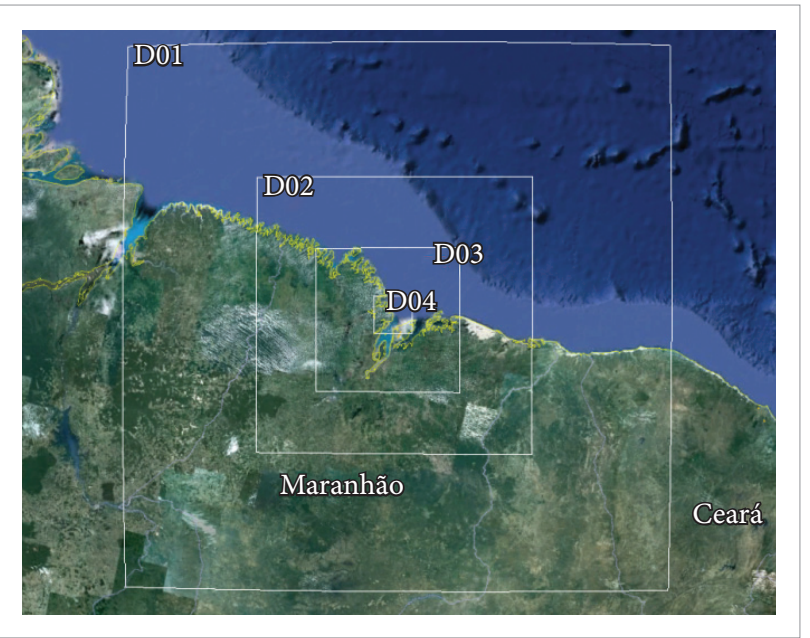

Figure 4. The location and distribution of the domains modeled in WRF Model. 


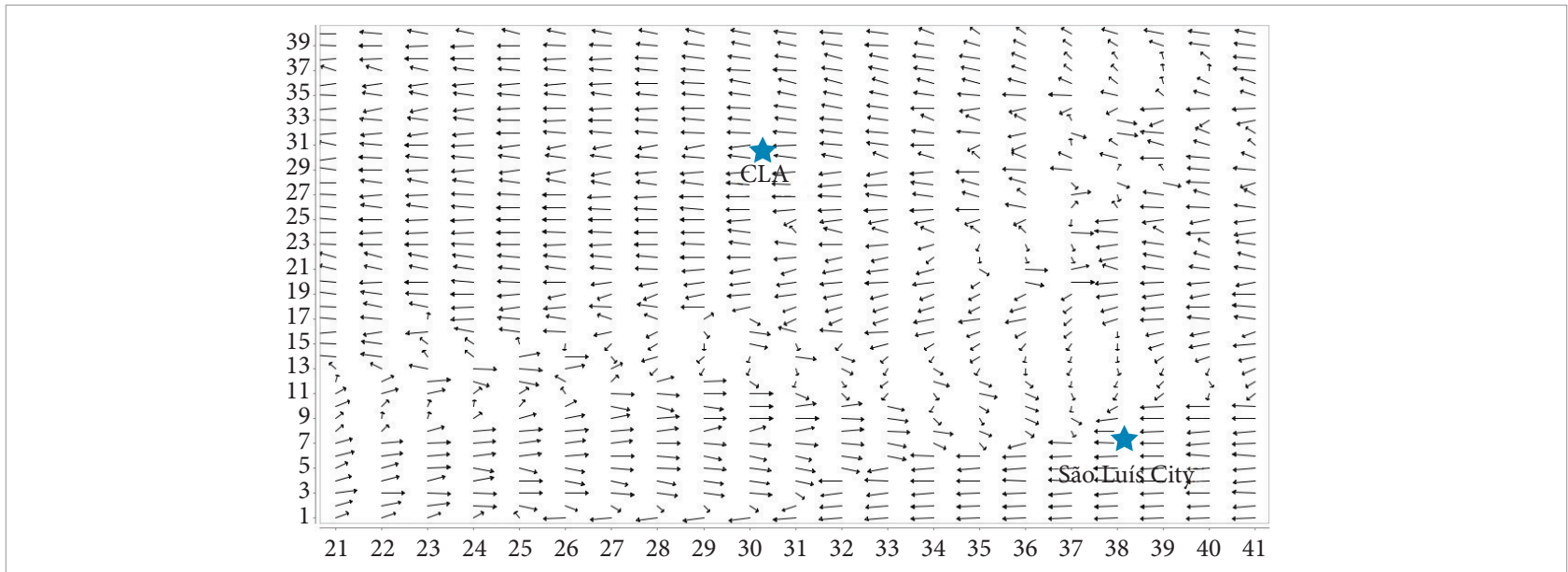

Figure 5. The surface wind field on April $2^{\text {nd }}, 2010$, at the time of the launching.

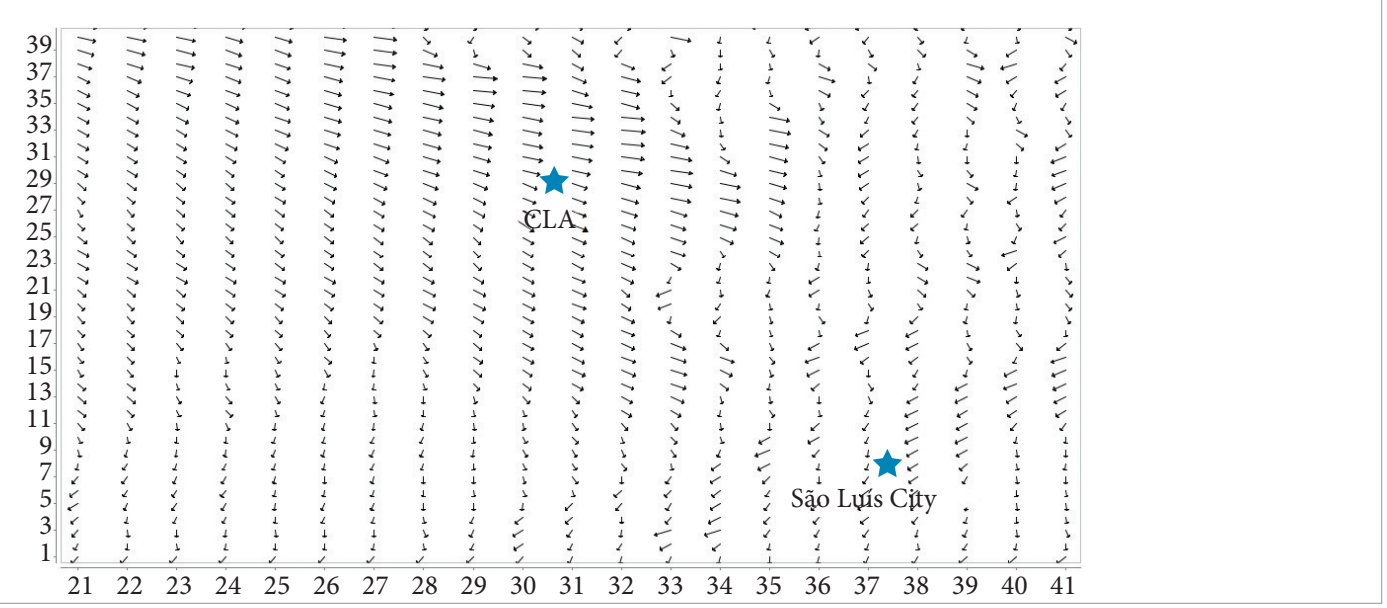

Figure 6. The surface wind field in domain 4 at 9PM, when it changed to the direction of São Luís.

\section{BUILDING THE EMISSIONS FILE}

The emission file is the critical point in the air quality context. To this end, it was developed the Sparce Matrix Operator Kernel System (SMOKE), which is used in order to generate the input information from emissions compatible with the model (Borge et al., 2008). In this study we did some adaptations in the SMOKE system to work with rocket launching emissions, which has some particularities that we had to address to in the system. The system has been applied to the CLA to process a hypothetical emission inventory for a test.

Figure 7 shows the launching of Titan IV, in Cape Canaveral, USA, and the formation of the so called ground-cloud and contrailcloud (Nyman, 2009). It has been a practice in USA to consider only the emissions from ground to $3000 \mathrm{~m}$ in simulations, and the emission rate of a normal rocket launch is $5,2 \times 10^{5} \mathrm{~g} / \mathrm{s}$ (Bjorklund et al., 1982).
Since SMOKE was not designed to deal with such kind of source, for each vertical level below 3,000 m, a virtual stack source emitting a certain hypothetical amount of the total emissions was configured, following the distribution presented in Table 1. These constituents are supposed to be released by the Brazilian Satellite Vehicle Launcher, for instance. Each virtual stack was positioned in the middle of its respective level. The virtual stacks located nearest to the ground have the main contribution in the emissions of simulating the ground-cloud effect. The remaining emissions were distributed along the highest levels. Input parameters, which entail significant uncertainty, were treated in a conservative fashion, in the sense that choices were made in order to favor overestimating rather than underestimating the toxic chemical concentrations being evaluated for the environmental assessment study. For example, we assume that all the material released by the rocket remains in the area below $3,000 \mathrm{~m}$. 
The emissions inventory was composed of only one pollutant, representing the combustion gases of the propellant. Table 2 shows the distribution of compounds that are emitted during the combustion, and their corresponding species in the chosen chemical mechanism (Bjorklund et al., 1982). For this simulation, we considered the three major emitted compounds: carbon monoxide (CO), hydrogen chloride $(\mathrm{HCl})$ and alumina (solid $\mathrm{Al}_{2} \mathrm{O}_{3}$ ). It is

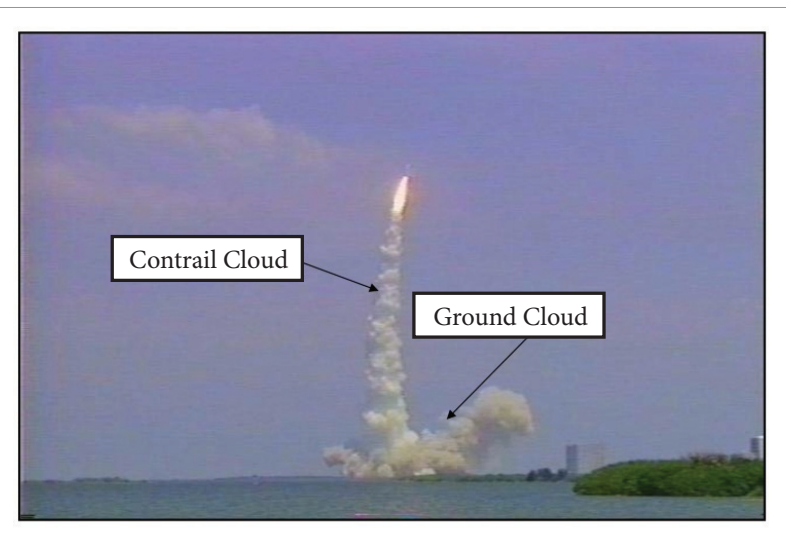

Figure 7. Illustration of the formation of the ground and contrail clouds, during a rocket launch (Nyman, 2009).

Table 1. Hypothetical distribution of the total emissions along the levels represented by their corresponding virtual stack.

\begin{tabular}{|c|c|c|}
\hline $\begin{array}{c}\text { Virtual Stack } \\
\text { Id }\end{array}$ & $\begin{array}{c}\text { Stack Height } \\
\text { (m) }\end{array}$ & $\begin{array}{c}\text { Distribution of } \\
\text { Total Emissions [\%] }\end{array}$ \\
\hline 0 & 11 & 20 \\
\hline 1 & 53 & 30 \\
\hline 2 & 81 & 10 \\
\hline 3 & 120 & 7 \\
\hline 4 & 180 & 6 \\
\hline 5 & 233 & 5 \\
\hline 6 & 285 & 5 \\
\hline 7 & 524 & 4 \\
\hline 8 & 704 & 4 \\
\hline 9 & 1446 & 3 \\
\hline 10 & 2195 & 3 \\
\hline 11 & 2788 & 3 \\
\hline
\end{tabular}

important to mention that only the emissions from the rocket launch were considered in this work. Regarding temporal allocation the temporal profiles were setup in SMOKE, in order to have the entire emissions only at noon (time of the hypothetical launch).

\section{CONFIGURING THE COMMUNITY MULTI-SCALE AIR QUALITY (CMAQ] MODEL}

For this study, we used the CMAQ model, version 5.0.1. Though our work has no intention to evaluate the impact of the emissions in the region, but only to study how we can apply CMAQ to such case, we chose to evaluate how it would impact the environment in this situation. Table 3 shows the options used in order to build the CMAQ. No initial or boundary conditions were applied, and the photolysis rates were calculated by the photolysis rate preprocessor (JPROC) using a table of clear-sky photolysis rates (or J-values) for a specific date according to the selected options used in order to build the CMAQ.

Table 2. Basic composition of the combustion gases of the propellant.

\begin{tabular}{|c|c|}
\hline Product & $\% \mathrm{~m} / \mathrm{m}$ \\
\hline Carbon Dioxide $\left(\mathrm{CO}_{2}\right)$ & 4.4 \\
\hline Carbon Monoxide $(\mathrm{CO})$ & 27.6 \\
\hline Hydrogen Chloride $(\mathrm{HCl})$ & 21.6 \\
\hline Alumina $\left(\mathrm{Al}_{2} \mathrm{O}_{3}\right.$ sólido) & 28.2 \\
\hline Water $\operatorname{Vapor}\left(\mathrm{H}_{2} \mathrm{O}\right)$ & 7.0 \\
\hline Nitrogen $\left(\mathrm{N}_{2}\right)$ & 8.4 \\
\hline Hydrogen $\left(\mathrm{H}_{2}\right)$ & 2.8 \\
\hline
\end{tabular}

Table 3. List of the options used in Community Multi-scale Air Quality, for this work.

\begin{tabular}{|c|c|}
\hline Property & Selected Option \\
\hline Gas Chemistry & cb05tucl_ae6_aq \\
\hline Aerosol Chemistry & aero6 \\
\hline Advection & vwrf \\
\hline Vertical Diffusion & acm2 \\
\hline Solver & ebi_cb05tucl \\
\hline Cloud Module & cloud_acm_ae6 \\
\hline
\end{tabular}




\section{RESULTS AND DISCUSSIONS}

Figure 8 shows a sequential tile plot for alumina, which was modeled as fine particulate matter (PMFINE), and Fig. 9 shows a sequential tile plot for carbon monoxide, both at the first level, at an approximate $20 \mathrm{~m}$ height. In these figures, we can see how the ground cloud behaviors after the rocket launch. Initially, it presents high concentrations at the location where the launching occurred, and after the first hour it presents a sensible decrease in the concentrations.
Six hours later the ground cloud was totally dispersed from the domain.

Figures 10 and 11 show a sequential 3D plot for both alumina and carbon monoxide, respectively. As it can be observed, these figures shows the same behavior, where we can easily identify the ground cloud and contrail cloud formed after the launching. In the subsequent hours, most of the concentrations remain near the ground.

Hydrogen chloride emissions were present in a considerable amount (Fig. 12), which led to harmful

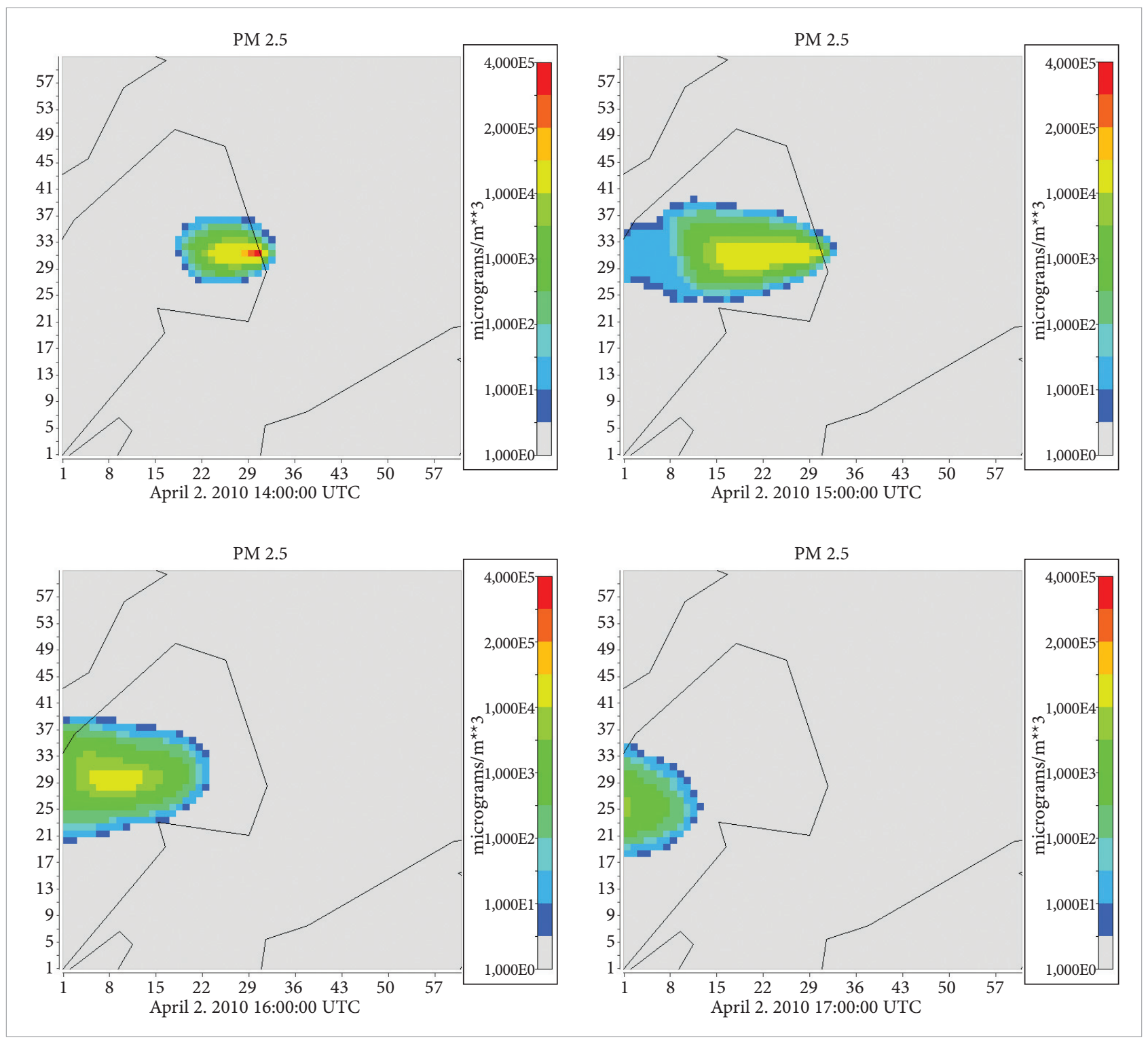

Figure 8. Sequential tile plot for $\mathrm{PM}_{2.5}$, representing the concentrations of alumina, for the first layer. 

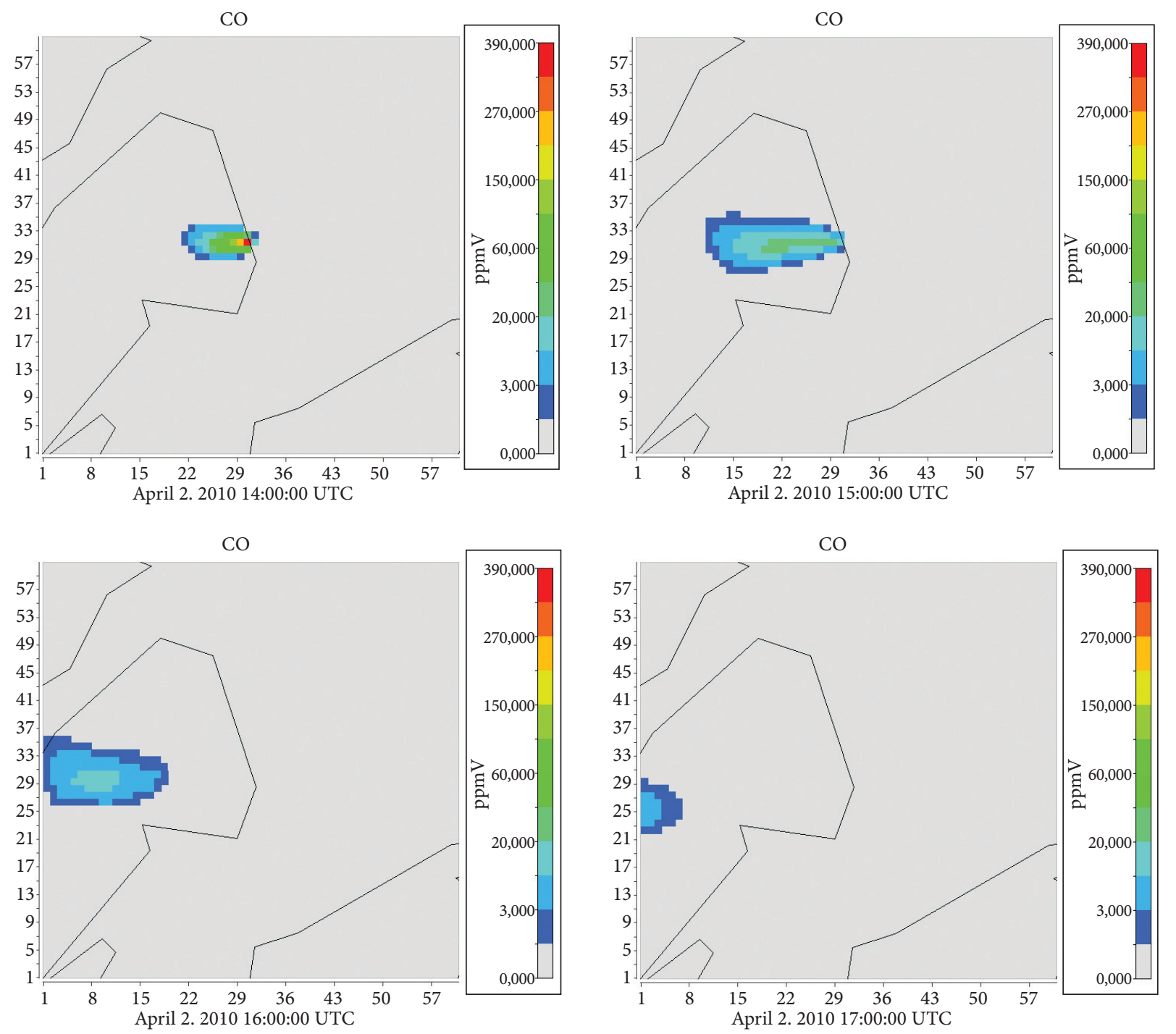

Figure 9. Sequential tile plot for CO for the first layer.
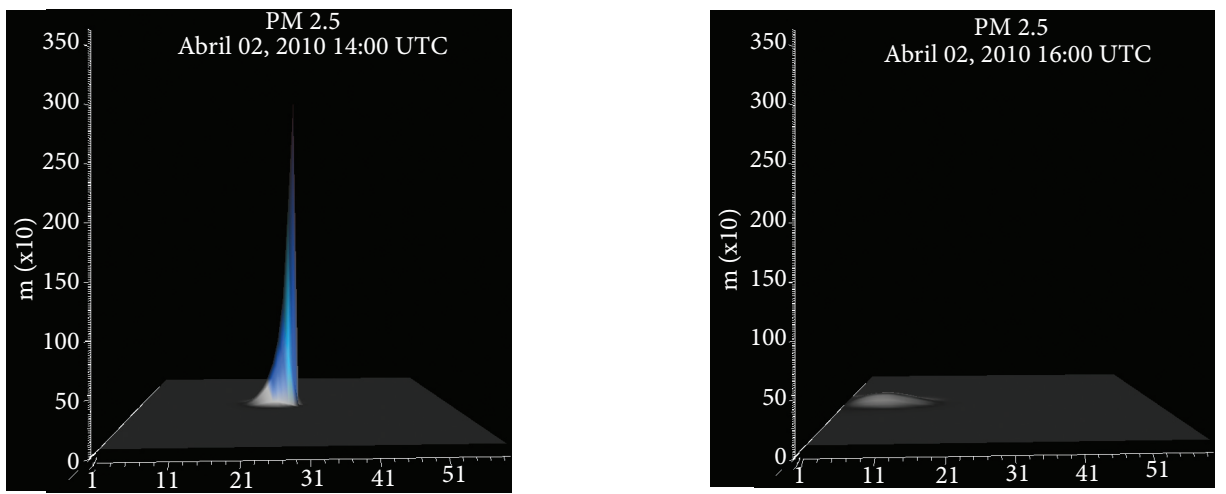

Figure 10. Sequential 3D plot for PM 2.5. 

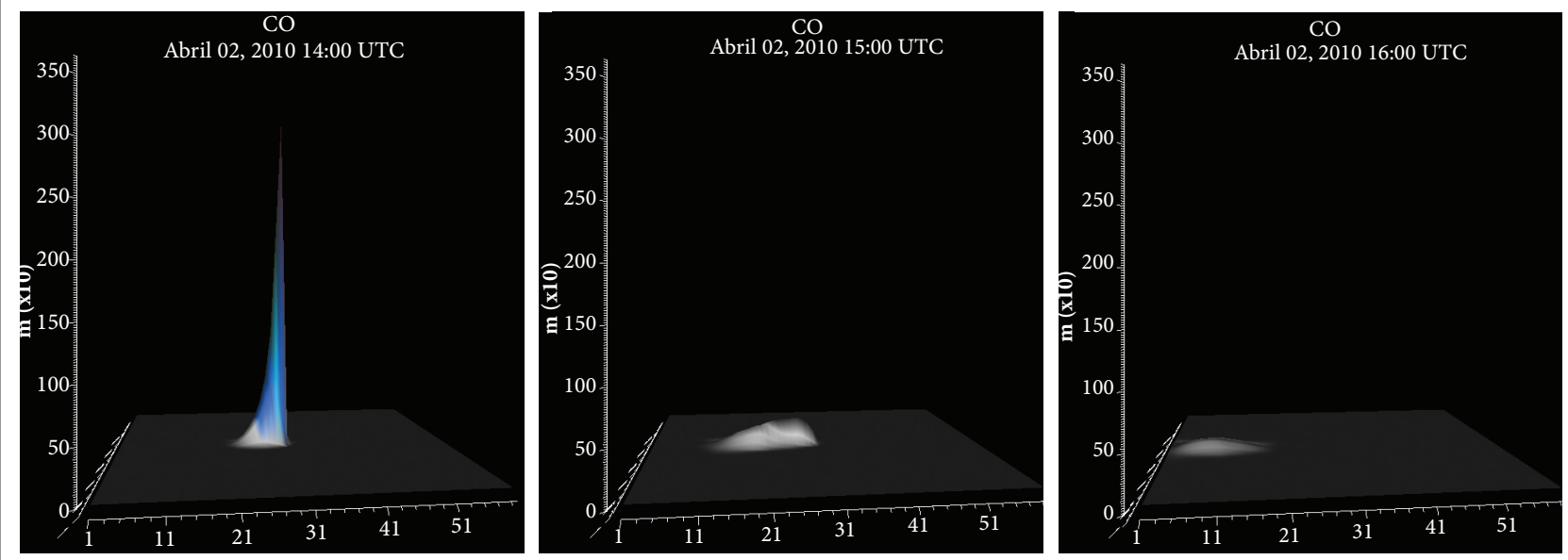

Figure 11. Sequential $3 \mathrm{D}$ plot for $\mathrm{CO}$.

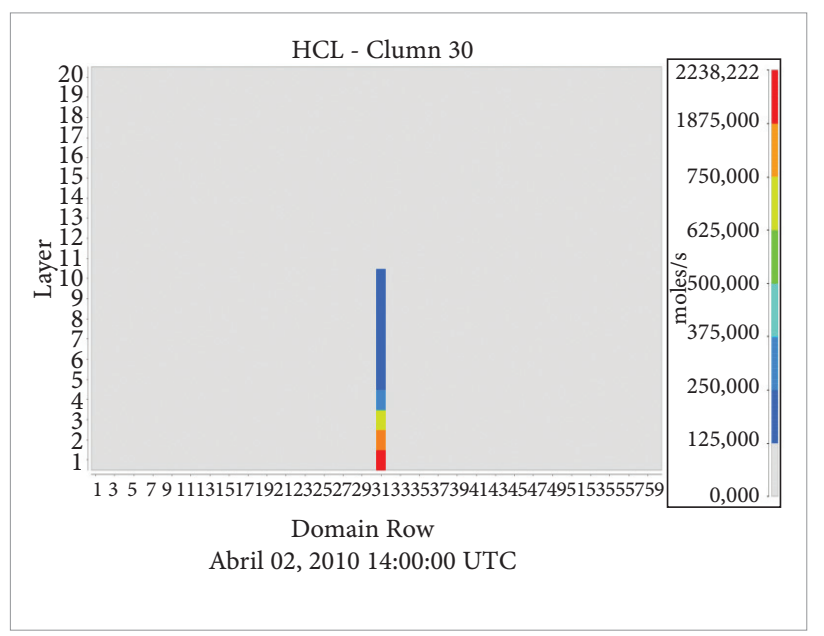

Figure 12. Vertical cross section plot of the emissions of hydrogen chloride. The emissions near ground are in the order of 2,000 moles/s.

Table 4. Health effects of respiratory exposure to hydrogen chloride (HCl).

\begin{tabular}{|c|c|}
$\begin{array}{c}\text { Exposure } \\
\text { Limits }(\mathrm{ppm})\end{array}$ & Health Effects \\
\hline $5<$ & Coughing \\
\hline 35 & $\begin{array}{c}\text { Throat irritation occurs after only a short time } \\
\text { Severe breathing difficulties and skin } \\
\text { inflammation or burns }\end{array}$ \\
\hline $10-50$ & $\begin{array}{c}\text { Maximum level that can be sustained for } \\
\text { several hours }\end{array}$ \\
\hline $100<$ & Swelling of the lungs and often throat spasm \\
\hline $50-1,000$ & Maximum possible exposure: 1 hour \\
\hline $1,000-2,000$ & Very dangerous even for a very short exposure \\
\hline
\end{tabular}

concentration levels in CMAQ. Table 4 (Baxter et al., 2000) presents the hydrogen chloride exposure limits, in ppm, and their impact in human health. $\mathrm{HCl}$ is a colourless gas with an irritating pungent odour perceivable at $0.8 \mathrm{ppm}$ (Lide, 2003). Figure 13 presents the sequential tile plot for $\mathrm{HCl}$ at the first level. The first hour shows the higher concentrations at the launch site, with concentration levels between 100-1,000 ppm. According to Table 4, at this region, the maximum exposure time is only 1 hour, causing swelling of the lungs, throat spasm and irritation. In the surrounding area, it presents concentration levels between 35-50 ppm, and even at the second hour, the concentration still remains in a dangerous level (5-35 ppm).

Based on the results, it is considered that the use of CMAQ to model rocket launch cases is very interesting and promising. Some difficulties were faced, which had to be addressed in order to run the model. One of the biggest challenges here was on how to properly build the emissions file. Although the configuration and the running of the SMOKE, in this case, were manageable, it was considered that a specific tool should be created in order to achieve this purpose. The results of the concentrations of $\mathrm{HCl}, \mathrm{CO}$ and $\mathrm{PM} 2.5\left(\mathrm{Al}_{2} \mathrm{SO}_{3}\right)$ showed to be very interesting: the formation of the ground and contrail cloud and the dispersion of the ground cloud were very clear in the simulations, and the concentration levels of $\mathrm{HCl}$, reported by the model, showed the importance to assess the impact of rocket launch events in the environment and human health, since chlorine has a major impact in the emissions of the combustion gases of the propellant during rocket launch events. 

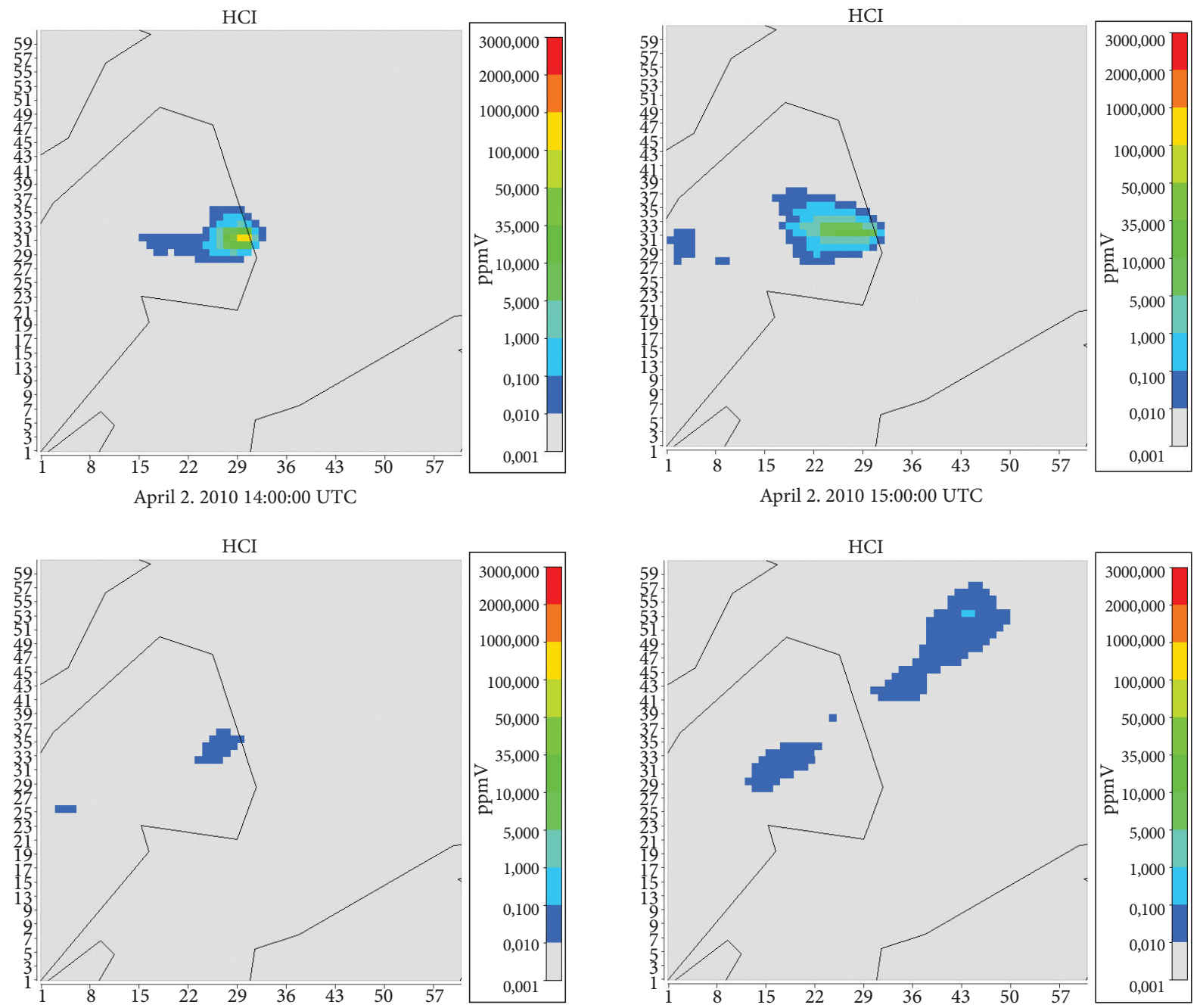

$\mathrm{HCI}$
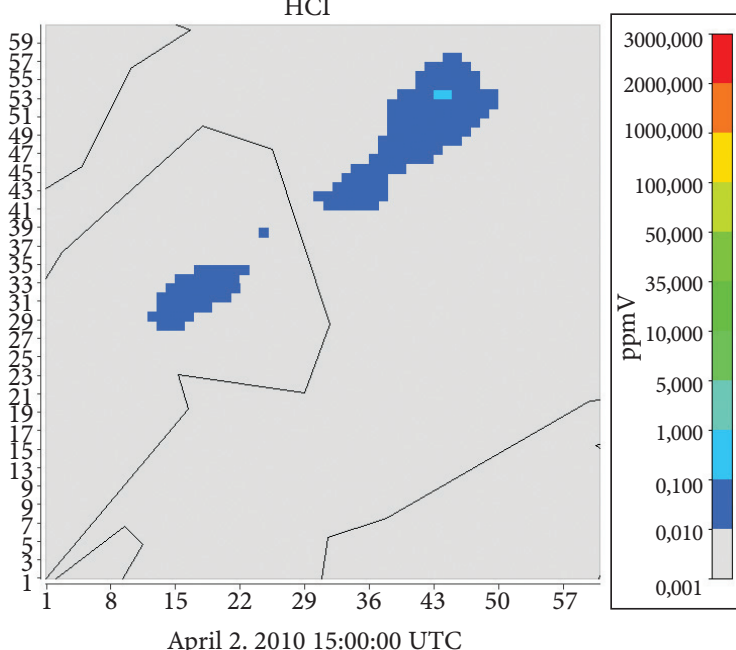

April 2. 2010 15:00:00 UTC
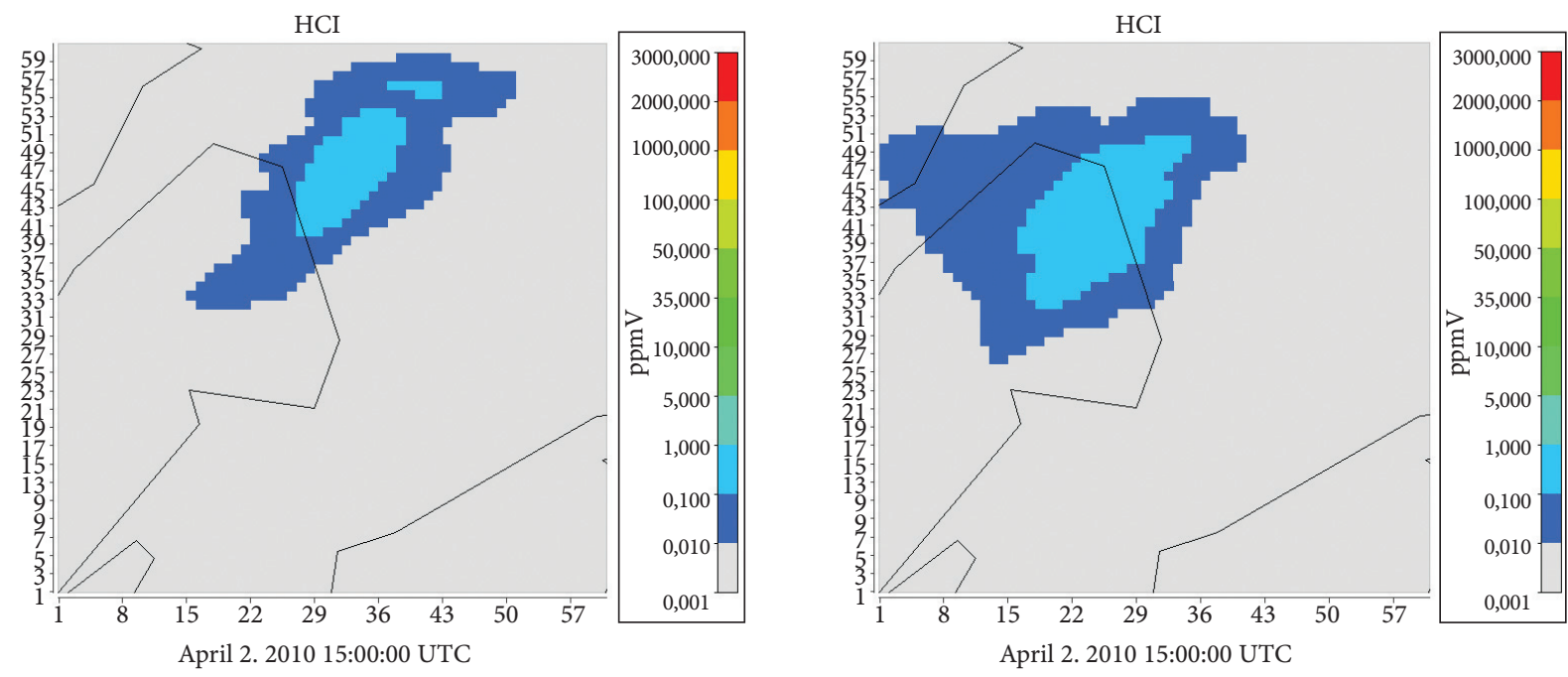

Figure 13. Sequential tile plot for $\mathrm{HCl}$ for the first layer. 


\section{SUMMARY AND PERSPECTIVES}

In this work, our main purpose was to apply CMAQ as a numerical model to simulate the dispersion of the contaminants emitted during a normal rocket launch event and to evaluate the entire CMAQ suite - model and its accessories - for this case. Since it is a first step towards providing a framework which will allow the development of a more meaningful model considering the Brazilian site characteristics, in CLA, we found that the use of the model for this case is quite promising. These results show that there is a need for thorough checking of the schemes with experimental observations planned in the region. We focus our attention in the future to evaluate the construction of the cloud released by the rocket, which can be initially defined as a single cloud that grows and moves, but remains the same during the formation of its ascending phase (ground cloud). This will address the different spatial and temporal scales of the problem more consistently. For more details about this, see the work of Moreira et al. (2011). For this purpose, we plan to develop a tool that is capable of calculating the formation of the cloud, from the moment it is released to the moment when it stabilizes in the atmosphere, then to build the emissions file accordingly to the input into the CMAQ. Furthermore, it is important to construct numerical experiments from the CMAQ system model in order to have them compared to the concentration results of the MSDEF model (Moreira et al., 2011), which is a very good and proven tool for a fast screening of the contaminant concentration field during rocket launch events.

\section{ACKNOWLEDGEMENTS}

The authors thank the Conselho Nacional de Desenvolvimento Científico e Tecnológico (CNPq) and the Coordenação de Aperfeiçoamento de Pessoal de Nível Superior (CAPES) for the partial financial support of this work.

\section{REFERENCES}

Baxter, P.J., Adams P.H., Aw, T.-C., Cockcroft, A. and Harrington, J.M., 2000, "Hunter's Diseases of Occupations", Arnold, London, Vol. 45, No. 2, pp. 123-178. doi: 10.1016/S0003-4878(00)00067-3.

Borge, R., Lumbreras, J. and Rodriguez, E., 2008, "Development of a High-Resolution Emission Inventory for Spain Using the SMOKE Modelling System: A Case Study for the Years 2000 and 2010", Environmental Modelling \& Software, Vol. 23, pp. 1026-1044.

Bjorklund, J.R., Dumbauld, J.K, Cheney, C.S. and Geary, H.V., 1982 "User's Manual for the REEDM (Rocket Exhaust Effluent Diffusion Model) Computer Program", NASA contractor report 3646. NASA George C. Marshall Space Flight Center, Huntsville, AL.

Byun, D.W. and Ching, J.K.S., 1999, "Science algorithms of the EPA Models-3 Community Multiscale Air Quality (CMAQ) Modeling System", EPA/600/R-99/030, Office of Research and Development, United States Environmental Protection Agency, Washington, DC.

Byun, D. and Schere, K.L., 2006, "Review of the Governing Equations, Computational Algorithms, and Other Components of the Models3community Multiscale Air Quality (CMAQ) Modeling System", Appl. Mech. Rev., Vol. 59, pp. 51-77.

Lide, D.R., 2003, "CRC Handbook of Chemistry and Physics", 84th edition. CRC Press, Boca Raton, Florida.

Moreira, D.M., Trindade, L.B., Fisch, G., Moraes, M.R., Dorado, R.M. and Guedes, R.L., 2011 "A Multilayer Model to Simulate Rocket Exhaust Clouds". Journal of Aerospace Technology and Management, Vol.
3, pp. 41-52. doi: 10.5028/jatm.2011.03010311

Nappo, C.J. and Essa, K.S.M., 2001, "Modeling Dispersion from NearSurface Tracer Releases at Cape Canaveral, Florida". Atmospheric Environment, Vol. 35, pp. 3999-4010.

Nyman, R.L., 2009, "NASA Report: Evaluation of Taurus II Static Test Firing and Normal Launch Rocket Plume Emissions".

Pires, L.B.M., Avelar, A.C., Fisch, G., Roballo, S.T., Souza, L.F., Gielow, R. and Girardi, R., 2009, "Studies Using Wind Tunnel to Simulate the Atmospheric Boundary Layer at the Alcântara Space Center". Journal of the Aerospace and Technology Management, Vol. 1, No. 1, pp. 91-98. doi: 10.5028/jatm. 2009.01019198.

Rao, R.M., Sinha, K., Candler, G.V., Wright, M.J. and Levin, D.A., 2001, "Numerical Simulation of Atlas ॥ Rocket Motor Plumes", 39th AIAA Aerospace Sciences Meeting and Exhibit, Reno, NV.

Reis, R.J., Aucoin, P.J. and Stechman, R.C., 1970, "Prediction of Rocket Exhaust Flow Fields", Journal of Spacecraft and Rockets, Vol. 7, No. 2, pp. 155-159. doi: 10.2514/3.29891.

Silva, A.F.G. and Fisch, G., 2014, "Avaliação do Modelo WRF para a Previsão do Perfil do Vento no Centro de Lançamento de Alcântara", Brazilian Journal of Meteorology, In press.

Skamarock, W.C. and Klemp, J.B., 2008, "A Time-Split Nonhydrostatic Atmospheric Model for Weather Research and Forecasting Applications", Journal of Computational Physics, Vol. 227, pp. 3465-3485. doi:10.1016/j.jcp.2007.01.037. 